\title{
POLYETHYLENE GLYCOL EFFECT ON THE TRANSIENT AND STEADY STATE PHASES OF P-NITROPHENYLTRIMETHYL ACETATE HYDROLYSIS CATALYZED BY $\alpha$-CHYMOTRYPSIN
}

\author{
CRISTIAN CALDERÓN* AND EDUARDO LISSI
}

\author{
Facultad de Química y Biología, Universidad de Santiago de Chile, USACH \\ This work is dedicated to the memory of Elsa Abuin and Guillermo Contreras
}

(Received: July 22, 2013 - Accepted: September 3, 2013)

\begin{abstract}
The effect of polyethylene glycol (PEG) on the hydrolytic activity of $\alpha$-chymotrypsin has been studied using p-nitrophenyltrimethyl acetate (PNTMA) as substrate. This substrate requires long times to reach the steady state condition, allowing the measurement by conventional methods of the fast initial "burst" step present on the biphasic catalytic behaviour exhibited by $\alpha$-chymotrypsin.

The presence of PEG increases both the initial and steady state rates of the reaction. This increase was observed at all the substrate concentrations employed. A formal Michaelis-Menten treatment under steady state conditions shows that $\mathrm{K}_{\mathrm{M}}$ remains almost constant over the range of PEG concentrations studied (up to $20 \% \mathrm{w} / \mathrm{v})$, whereas $\mathrm{k}_{\text {cat }}$ moderately increases with the increment in PEG concentration.

The results obtained in this work are interpreted in terms of the following mechanism:
\end{abstract}

Keywords: Enzyme kinetics, chymotrypsin, p-nitrophenyl trimethylacetate, poly-ethyleneglycol

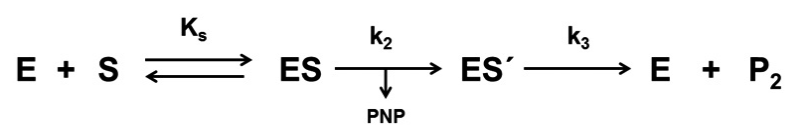

A calculation of $\mathrm{k}_{2}, \mathrm{k}_{3}$ and $\mathrm{K}_{\mathrm{s}}$, derived form this mechanism of $\alpha$-chymotrypsin reveals that PEG influences mainly $k_{2}$ and $k_{3}$, leaving $K_{8}$ unmodified at the polymer concentrations considered. The observed effect of PEG could be related to its influence upon the acyl-enzyme complex (ES') with almost $99 \%$ of the enzyme complexed over the range of PEG concentrations employed.

\section{INTRODUCTION}

Studies on the effect of macromolecules on the catalytic activity of enzymes are of interest due to the fundamental role of these processes in living organisms and their wide range of industrial applications. Studies of enzyme activity of biological relevance are currently carried out in diluted solutions. Such environments are different from those in which enzymes perform their biological function, where normally are present a large variety of other macromolecules that can modify the rate of the catalytic process.

The presence of macromolecules on the media can modulate the activity of the enzyme in a rather complex fashion. However, three main phenomena (individually or combined) can explain the changes observed in the enzyme activity: effect of the added macromolecule on the free substrate concentration, enzyme macromolecule interactions and excluded volume effects.

Changes in free substrate concentration due to the presence of macromolecules (i.e. transport proteins) is a factor worth to be considered regarding its influence on enzymatic activity. The effect of the addition of albumin on the acyl chain specificity of lipase towards a series of triacylglicerols of various acyl-chain lengths as substrates was evaluated by Wang and col. ${ }^{1}$. These authors concluded that the inhibitory effect of albumin on the lipase catalysed hydrolysis of trihexanoylglycerol can be explained in terms of the high affinity of albumin towards this substrate.

Another factor to be accounted for into the analysis of the effect of the presence of macromolecules into enzymatic activity is related to the enzyme/ macromolecule interaction. Calderón et al. ${ }^{2}$, on the study of the effect of human serum albumin (HSA) on the rate of hydrolysis of 4-methylumbelliferyl- $\beta$-D$N-N^{\prime}-N^{\prime \prime}-\beta$-D-glucoside catalyzed by egg hen white lysozyme, revealed that the presence of albumin decreases $\mathrm{k}_{\text {cat }}$ for the reaction leaving $\mathrm{K}_{\mathrm{M}}$ unmodified. The observed variation on the kinetic behaviour evidenced was explained in terms of the occurrence of the interaction HSA/Lysozyme, mainly due to the correspondence between the variation of the catalytic rate constant and the decrease of the free enzyme concentration.

In complex media, high concentration of macromolecular agents such as proteins, polysaccharides, synthetic polymers, etc. effects of excluded volume, commonly known as molecular crowding effects, are evidenced. Assad and Engberts ${ }^{3}$, studied the kinetics of the hydrolysis of p-nitrophenyl acetate (PNA) catalysed by trypsin in the presence of poly ethylene glycol (PEG). The increase in PEG concentration causes a moderate decrease in $\mathrm{k}_{\mathrm{cat}}$ while $\mathrm{K}_{\mathrm{u}}$ remains constant over the range of PEG concentrations studied (up to $395 \mathrm{~g} \mathrm{~L}^{-1}$; $\mathrm{M}_{\mathrm{W}}=8000$ ). On a similar topic, Derham and Harding ${ }^{4}$, studied the effect of the addition of Dextran, PEG and Carbopol upon the activity of urease, evidencing for all the polymers studied a decrease on urease activity. The observed effect was explained in terms of a viscosity effect that slows the reaction due to a restricted diffusion of the reagents.

$\alpha$-Chymotrypsin $(\alpha-\mathrm{CT})$ is a water-soluble enzyme $(25 \mathrm{kDa}$; $\mathrm{pI}=8.3)$ that catalyzes the hydrolysis of peptidic bonds in proteins, being able to act both upon amide and ester linkages ${ }^{5-8}$. The activity of the enzyme is modified by the presence of lipid/water interfaces and extensive studies have been reported regarding the characteristics of the process in reverse micellar solutions ${ }^{9-11}$ and surfactants solutions below and above their $\mathrm{CMC}^{12-15}$. Regarding its behaviour in the presence of macromolecules, it has been reported that the presence of HSA decreases the rate of hydrolysis of N-glutaryl-L-phenylalanine p-nitroanilide (GPNA) ${ }^{16}$ but correction of the Michaelis-Menten parameter taking into account de decrease in free substrate, showed that both $\mathrm{k}_{\text {cat }}$ and $\mathrm{K}_{\mathrm{M}}$ remains almost independent of the presence of albumin, demonstrating that the depletion of the substrate is the main factor influencing the activity of the enzyme in this system. Studies regarding the behaviour of $\alpha$-CT in the presence of polyethylene glycol has also been performed ${ }^{17}$. It has been reported that the presence of the polymer increases the reaction rate in the steady state stage of the hydrolysis of p-nitrophenyl acetate catalysed by $\alpha$-chymotrypsin.

In the present work we present data obtained in the hydrolysis of p-nitrophenyltrimethyl acetate catalysed by $\alpha$-chymotrypsin. This substrate shows the same behaviour as the commonly used p-nitrophenyl acetate but, due to the presence of the bulky trimethylacetate group (which introduces a steric hindrance that stabilizes the acyl-enzyme complex), PNTMA requires longer times to reach the steady state condition ${ }^{18}$, allowing an evaluation of the kinetics of the whole enzymatic process, particularly for the transient phase of the $\alpha$-chymotrypsin mechanism, by conventional procedures ${ }^{19}$.

\section{MATERIALS AND METHODS}

\section{Reagents and equipment}

$\alpha$-Chymotrypsin ( $\alpha$-CT, Type II, from bovine pancreas), polyethylene glycol (PEG, nominal molecular weight 3,400) and p-nitrophenyltrimethylacetate (PNTMA) from Sigma were used as received. Ultrapure water obtained from a Barnstead easy pure II equipment was employed to prepare all the solutions. All measurements were performed at $25^{\circ} \mathrm{C}$ in TRIS/HCl buffer $(\mathrm{pH}=7.0)$. Absorption spectra and absorbances were recorded with a Hewlett-Packard 8453 UV-Visible spectrometer.

\section{Reaction rate measurements}

The rate of PNTA hydrolysis catalyzed by $\alpha$-CT, was measured at $25^{\circ} \mathrm{C}$ in aqueous buffered solution and in PEG (up to $20 \% \mathrm{w} / \mathrm{v}$ ) solutions at $\mathrm{pH}=$ 7 (10 mM TRIS-HCL buffer). The reaction was followed by registering the absorbance of p-nitrophenol (PNP, $440 \mathrm{~nm}, \varepsilon=17,700 \mathrm{M}^{-1} \mathrm{~cm}^{-1}$ ) released over the course of the reaction as a function of time. The extinction coefficient of 
PNP was independent of PEG concentration in the range of concentrations used in the present work. The reaction was initiated by the addition of an aliquot of a concentrated solution of $\alpha$-CT to a solution containing a given concentration of PNTMA in buffer (or PEG solution) in order to obtain a final enzyme concentration equal to $10 \mu \mathrm{M}$.

\section{RESULTS AND DISCUSSION}

The time course for the release of p-nitrophenol in the hydrolysis of p-nitrophenyltrymethyl acetate catalyzed by $\alpha$-chymotrypsin in absence and in the presence of polyethylene glycol is shown in Figure 1. Both in presence and absence of polyethylene glycol, the data show the two distinguishable "steps" characteristics of $\alpha$-chymotrypsin catalyzed processes ${ }^{18}$. A very fast initial rate or "burst" step is observed, followed by a decay in the rate of p-nitrophenol release until steady state conditions are achieved. The presence of polyethylene glycol increases both the initial and steady state rates of the reaction. This increase was observed at all the substrate concentrations employed $\left(2 \times 10^{-5}\right.$ to $\left.7 \times 10^{-4} \mathrm{M}\right)$

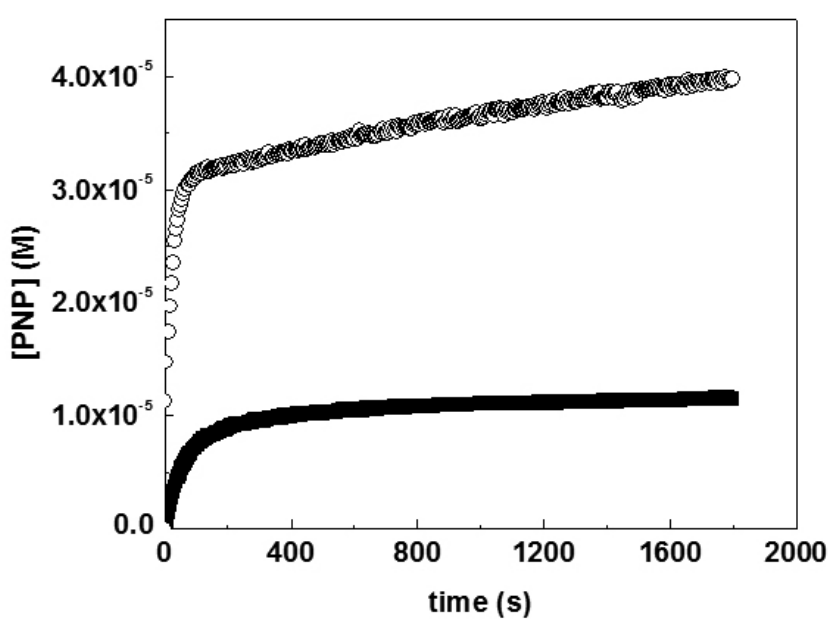

Figure 1. Time course of p-Nitrophenol (PNP) formation in the hydrolysis of p-nitrophenyl trymethyl acetate catalyzed by $\alpha$-chymotrypsin. In absence of PEG (@); $20 \%$ p/v PEG (०). PNTA $=7 \times 10^{-4} \mathrm{M}$.

In order to obtain some insight into the origin of the effect exerted by polyethylene glycol, a formal Michaelis-Menten treatment of the data obtained was performed. The dependence of $\mathrm{k}_{\text {cat }}$ and $\mathrm{K}_{\mathrm{M}}$ with the polyethylene glycol concentration is shown in Figure 2. For $\mathrm{K}_{\mathrm{w}}$, within the uncertainty of the data, a small increase is observed, indicating a negligible or non-existent effect of polyethylene glycol on the binding process that leads to the substrate/ enzyme complex formation. On the other hand, $\mathrm{k}_{\mathrm{cat}}$ shows a more significant dependence with the polyethylene glycol percentage, leading to an increase of $\mathrm{k}$ of almost 6 times from zero to $20 \%$ polyethylene glycol. Abuin et al. ${ }^{17}$ in a study on the effect of polyethylene glycol on the hydrolysis of p-nitrophenyl acetate catalyzed by $\alpha$-chymotrypsin, reported similar dependences of $K_{m}$ and $\mathrm{k}_{\text {cat }}$. In this system, $\mathrm{K}_{\mathrm{M}}$ remains constant over the range of PEG concentrations employed (up to $30 \% \mathrm{p} / \mathrm{v}$ PEG) and $\mathrm{k}$ shows a much smaller increase with PEG concentration than that found in the present work using p-nitrophenyltrymethyl acetate as substrate.

The $\alpha$-chymotrypsin catalytic mechanism is commonly represented by the following scheme.

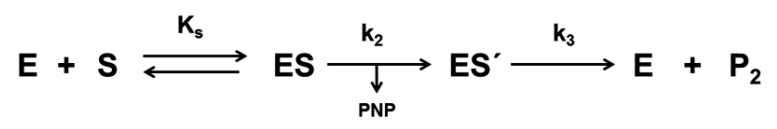

Where $\mathrm{E}$ is the free enzyme, ES the enzyme/substrate complex, $\mathrm{ES}^{\prime}$ the acyl-enzyme intermediate, PNP stands for $\mathrm{p}$-nitrophenol and $\mathrm{P}_{2}$ is the acetate moiety.

It can be demonstrated that, for the proposed mechanism, $\mathrm{k}_{\text {cat }}$ and $\mathrm{K}_{\mathrm{M}}$ can be expressed according to equations 1 and 2 :

$$
k_{C A T}=\frac{k_{2} k_{3}}{k_{2}+k_{3}}
$$

$$
K_{M}=\frac{k_{-1}}{k_{1}}\left[\frac{k_{3}}{\left(k_{2}+k_{3}\right)}\right]
$$

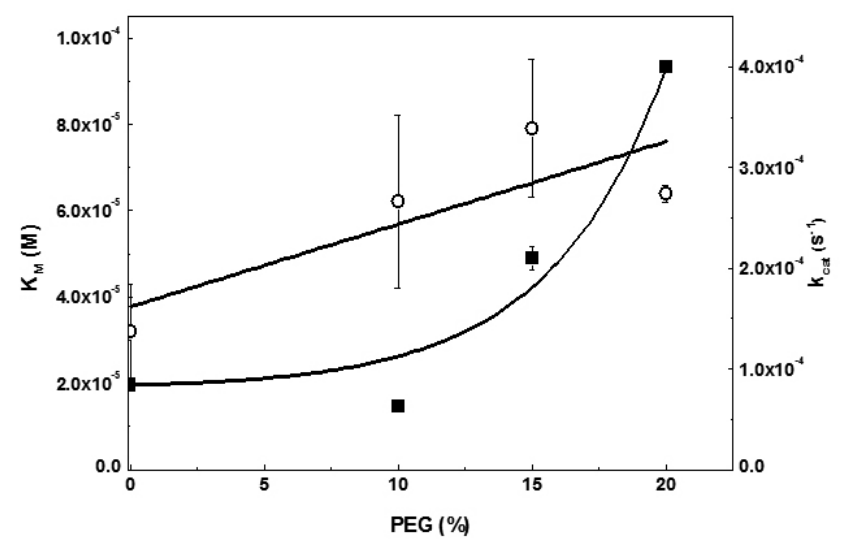

Figure 2. Dependence of $\mathrm{k}_{\text {cat }}$ and $\mathrm{K}_{\mathrm{M}}$ with $\mathrm{PEG}$ concentration. $\mathrm{k}_{\text {cat }}(\mathbf{m}) ; \mathrm{K}_{\mathrm{M}}$ (०). Each data point represents the mean of three independent experiments.

It is mandatory then, to delve into some explanation for the observed behavior of $\mathrm{k}_{\text {cat }}$ and $\mathrm{K}_{\mathrm{M}}$, to evaluate the effect of PEG on $\mathrm{k}_{2}, \mathrm{k}_{3}$ and the relationship $\mathrm{k}_{-1} / \mathrm{k}_{1}$ (more commonly expressed as $\mathrm{K}_{\mathrm{s}}$ ). According to the mathematical analysis developed by Bender et al. (14) on the study of the kinetic behavior of the hydrolysis of p-nitrophenyltrimethylacetate catalyzed by $\alpha$-chymotrypsin, the determination of the decay constant (b) from the curve obtained by subtracting the experimental PNP vs. time curve from the steady state straight line (Figure 3 ) allows the evaluation of $\mathrm{k}_{2}$ and $\mathrm{K}_{\mathrm{s}}$, based on the hyperbolic dependence between $\mathrm{b}$ and the substrate concentration proposed by the authors (Eq. 3)

$$
b=\frac{k_{2}[S]_{0}}{K_{S}+[S]_{0}}
$$

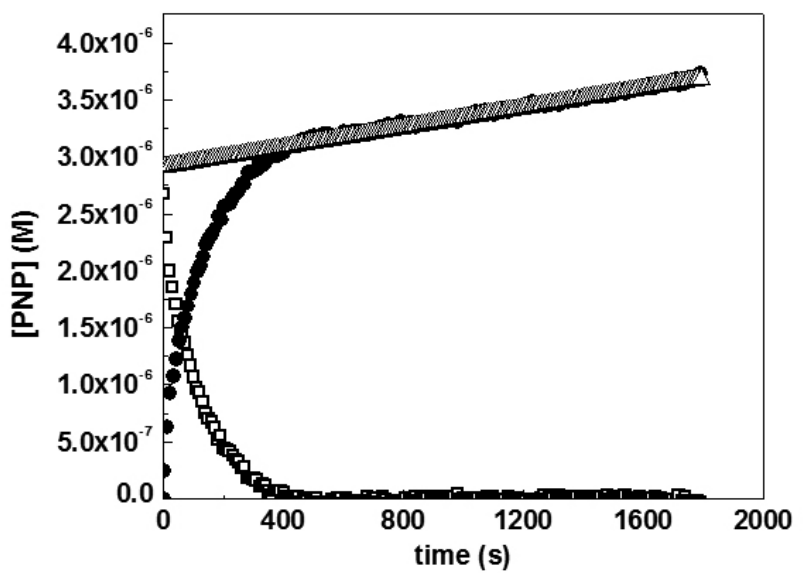

Figure 3. Schematic depiction of the mathematical treatment for the estimation of the parameter b. Experimental PNP vs. time plot $(\bullet)$; extrapolated steady state straight line $(\Delta)$; decay curve obtained by subtraction of $\bullet$ from $\Delta$. 
Figure 4 shows the treatment of the kinetic data according to Eq. 3 at different PEG concentrations. A hyperbolic dependence between the decay constant $\mathrm{b}$ and the substrate concentration was observed at PEG concentrations up to $20 \% \mathrm{w} / \mathrm{w}$. At the highest concentration of PEG considered, a tenfold increase in the exponential decay constant (at $7 \times 10^{-4} \mathrm{M}$ of PNTMA). The prevalence of the hyperbolic behavior allows an analysis of the dependence of $\mathrm{k}_{2}$ and $\mathrm{K}_{\mathrm{S}}$ for $\alpha$-chymotrypsin.witth PEG concentration.

The data obtained for $k_{2}$ is shown in Figure 5. The magnitude of $k_{2}$ readily increases with the increase of polyethylene glycol concentration, having a value almost ten times larger at $20 \%$ polyethylene glycol than the one determined in absence of polyethylene glycol. The presence of the polymer in the reaction media seems to have a considerable effect on the rate of the "burst" step of the $\alpha$-chymotrypsin catalytic mechanism. The variation of $\mathrm{k}_{3}$ is similar to that observed for $\mathrm{k}_{\text {cat }}$. This results from the fact that, according to eq. 1, being $\mathrm{k}_{2}$ much larger than $\mathrm{k}_{3} \mathrm{k}_{3}$ turns out to be equal to $\mathrm{k}_{\text {cat }}$ The values of $\mathrm{k}_{2}$ and $\mathrm{k}_{3}$ obtained allow to postulate that, in spite of the increase on the reaction rate of both the "burst" step and the stationary-state, the effect of polyethylene glycol on the activity of $\alpha$-chymotrypsin observed has its origin on its influence on the process of release of the second product (the acetate fragment) from the acylenzyme complex $\left(\mathrm{ES}^{\prime}\right)$

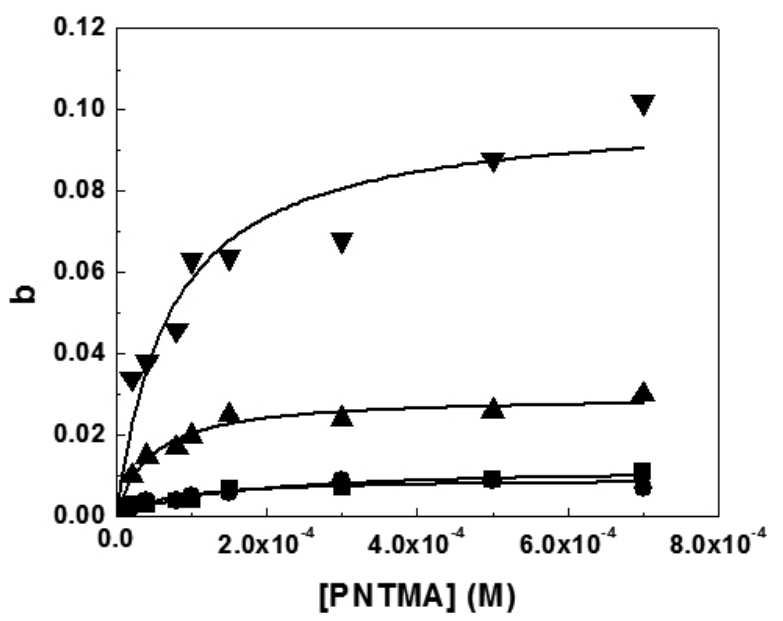

Figure 4. Dependence of the decay constant (b) with

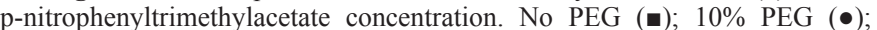
$15 \%$ PEG $(\boldsymbol{\Delta}) ; 20 \%$ PEG $(\boldsymbol{\nabla})$. Experiments were performed by triplicate. Nonlinear curve fit was performed according to eq. 3 using Origin (OriginLab Corp.) software.

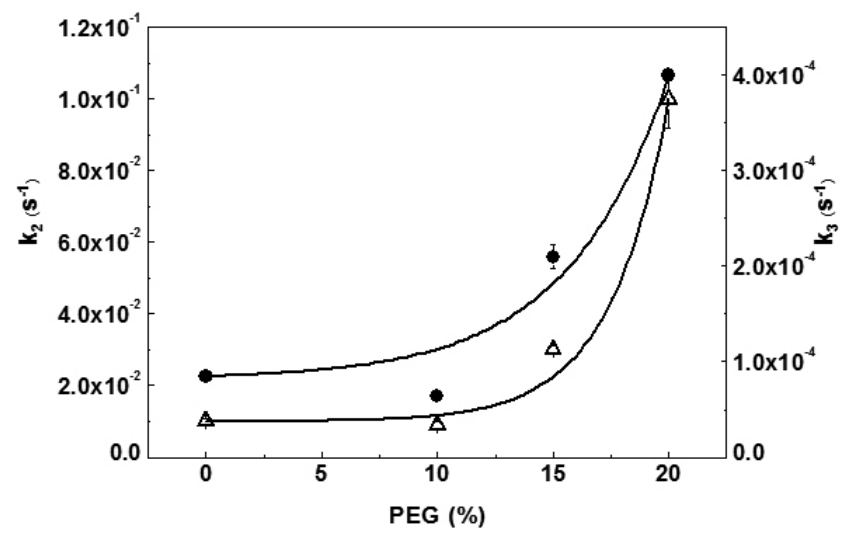

Figure 5. Dependence of $k_{2}$ and $k_{3}$ with PEG concentration. $k_{2}(\bullet) ; k_{3}$ $(\Delta)$. Experiments were performed by triplicate. The solid line represent the exponential fit of the data.
$\mathrm{K}_{\mathrm{S}}$ shows little variation with the polyethylene glycol concentration (Figure 6). This could explain the behavior exhibited by $\mathrm{K}_{\mathrm{M}}$. According to eq. $2, \mathrm{~K}_{\mathrm{M}}$ depends upon $K_{S}$ and the $k_{3} / k_{2}$ ratio (because of $k_{2}>>k_{3}$ ). It can be seen that $\mathrm{K}_{\mathrm{M}}$ remains relatively constant at all the polyethylene glycol concentrations employed, mainly because $\mathrm{K}_{\mathrm{S}}$ and the $\mathrm{k}_{3} / \mathrm{k}_{2}$ ratio remain essentially constant.

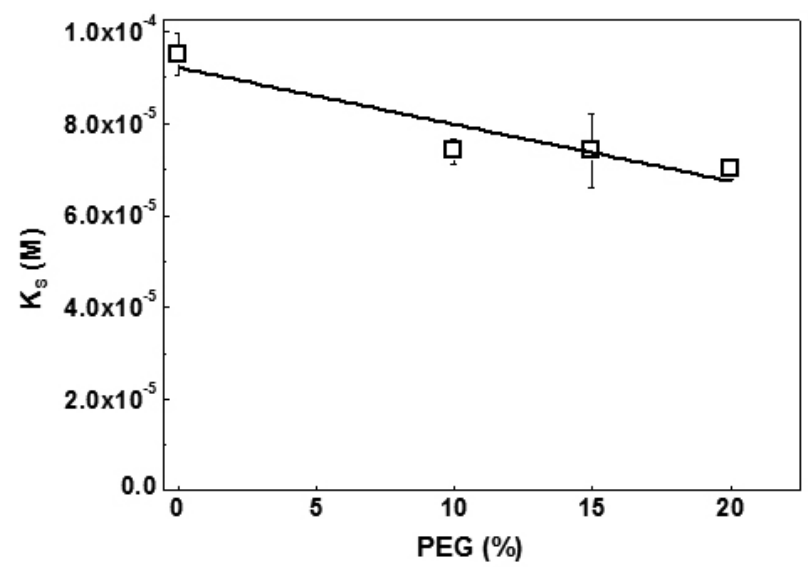

Figure 6. Dependence of Ks with PEG concentration. Data represent the mean of three independent experiments and was fitted according to a linear regression.

The effect of polyethylene glycol on the hydrolysis of p-nitrophenyltrimethyl acetate hydrolysis catalyzed by $\alpha$-chymotrypsin could be related to its influence upon the acyl-enzyme complex (ES'). Almost $99 \%$ of the enzyme is in the form of ES' over the range of PEG concentrations employed. This was estimated by the determination of the initial reaction rates $\left(\mathrm{V}_{0}\right)$ and the steady state rate $\left(\mathrm{V}_{\mathrm{ss}}\right)$ both extrapolated at infinite substrate concentration (Eq. 4)

$$
\propto=1-\frac{V_{S S}}{V_{0}}
$$

being $\alpha$ the fraction of enzyme in the form of the acyl-enzyme complex. Similar results are obtained by using the $\mathrm{k}_{3} / \mathrm{k}_{2}$ ratio (Eq. 5)

$$
\frac{1}{\propto}=1-\frac{k_{3}}{k_{2}}
$$

The presence of PEG on the reaction media seems to induce a decrease on the stability of $\mathrm{ES}^{\prime}$ favouring at the same time the transition between ES and $\mathrm{ES}^{\prime}$. This phenomena might be originated by conformational changes on the enzyme due to its interaction with PEG molecules. In spite of the lack of charge on PEG this interaction must involve a direct association between the protein and the polymer since excluded volume effects are not relevant at the polymer concentrations employed in this work. In fact, at the highest PEG concentrations employed ( $20 \%$ ) only $17 \%$ of the solution volume is occupied by the polymer ensemble. Further studies are required in order to ascertain these observations.

\section{CONCLUSIONS}

The increment of PEG concentration increases the rate of both the transient and steady state phase of the hydrolysis of p-nitrophenyltrimethyl acetate hydrolysis catalyzed by $\alpha$-chymotrypsin. The influence of polyethylene glycol is exerted mainly by inducing instability over the acyl-enzyme complex, while favoring the transition between the enzyme-substrate complex and the acyl-enzyme complex. The observed behavior seems to be related with conformational changes on the enzyme due to direct interaction with PEG molecules.

\section{ACKNOWLEDGMENTS}

This work has been supported by FONDECYT, Chile. 


\section{REFERENCES}

1. J-S. Wang, X. Wen, J.T. Backman, P.J Neuvonen. J. Pharmacol. Exp. Ther. 302:43 (2002).

2. C. Calderón, E. Abuin, E. Lissi, R. Montecinos, Protein J. 30:367 (2011).

3. N. Assad, J. B. F. N. Engberts, J. Am. Chem. Soc. 15, 6874 (2003).

4. B. K. Derham, J. J. Harding, Biochim. Biophys. Acta 1764, 1000 (2006).

5. N. Spetri, F. Alfani, M. Cantarella, F. D'Amico, E. Germani, G. Savelli. J. Mol. Catal. 6, 99 (1999).

6. P. Viparelli, F. Alfani, M. Cantarella. Biochem. J. 344, 765 (1999).

7. F. Alfani, F. M. Cantarella, N. Spetri, R. Germani, G. Savelli. Appl. Biochem. Biothechnol. 88, 1 (2000).

8. P. Viparelli,F. Allfani, M. Cantarella. J. Mol. Catal. B: 15, 1 (2001).
9. Y. Miyake, T. Owari, F. Ishiga, M. Teramoto. J. Chem. Soc. Faraday Trans. 90, 979 (1994).

10. F. M. Menger, K. Yamada. J. Am. Chem. Soc. 101, 6731 (1979).

11. L.F. Aguilar, E. Abuin, E. Lissi. Arch. Biochem. Biophys. 388, 231 (2001).

12. E. Abuin, E. Lissi, R. Duarte. Langmuir 19, 5374 (2003).

13. E. Abuin, E. Lissi, C. Calderón. J.Colloid Interf. Sci. 308, 573 (2007).

14. E. Abuin, E. Lissi, R. Duarte. J. Molec. Catal. 31, 83, (2004).

15. E. Abuin, E.Lissi. R. Duarte. J. Colloid Interf. Sci. 283, 539 (2005).

16. E. Abuin, E. Lissi, M. Ahumada. C. Calderón. Protein J. 30, 143 (2011).

17. E. Abuin, E. Lissi, R. Bridi. J. Chil. Chem. Soc. 56, 948 (2011).

18. M.L. Bender, F. Kèzdy, F. C. Wedler. J. Chem. Ed. 44, 84 (1967).

19. C.E. Mcdonalds, A.K. Balls. J. Biol. Chem. 227, 727 (1957). 